\title{
Tuberculum Sellae
}

National Cancer Institute

\section{Source}

National Cancer Institute. Tuberculum Sellae. NCI Thesaurus. Code C45911.

A prominence on the sphenoid bone, which separates the sella turcica from the chiasmatic sulcus. 